dit ook noodgedwongen beperkter heb moeten weergeven dan dat van het christendom. De simpele reden is dat de standpunten van eerstgenoemde stromingen nog maar weinig in bronnen is uitgewerkt. Ook dit is overigens in mijn boek te lezen.

\title{
Kosmopolieten rond de dorpspomp
}

\author{
Fred Wester
}

Gabriëls, R, Intellectuelen in Nederland. Publieke controversen over kernenergie, armoede en Rushdie. Amsterdam: Boom, 200I. 304 p. ISBN $90535258 \mathrm{I} 5 € 23,75$

Volgens de flaptekst verheldert René Gabriëls in dit proefschrift 'hoe vooral Nederlandse intellectuelen voor en van ideeën leven. Hij is nagegaan hoe zij intervenieerden in publieke controverses over kernenergie, armoede en Rushdie'. In het voorwoord maakt Gabriëls duidelijk dat het intellectuele klimaat in Nederland hem niet bevalt. In Nederland zijn intellectuelen doorgaans moralisten of ironici die in een soort double bind situatie met elkaar zijn verbonden, wat verstikkend is voor het intellectuele klimaat. Maar Gabriëls ontwaart de opkomst van de kosmopoliet die de traditionele intellectueel komt vervangen. In de inleiding probeert Gabriëls duidelijk te maken wat onder intellectuelen moet worden verstaan. Intellectuelen leven voor en van hun ideeën. Hier spelen drie kwesties: welke identiteit kan men de intellectueel toeschrijven, wat is zijn verantwoordelijkheid en in hoeverre is zijn positie in de samenleving veranderd? Hij bespreekt deze kwesties vanuit een moderne en een postmoderne benadering, maar dat levert weinig op als we willen weten wie nu eigenlijk worden bedoeld. De openbaarheid is het speelveld van de intellectuelen (p. 39), maar ook van de journalist en de politicus. Tussen de regels door wordt soms met intellectuelen gedoeld op hen die zich zo noemen, diegenen die deelnemen aan maatschappelijke discussies, wetenschappers, filosofen en columnisten. Een tentatieve definitie van een intellectueel luidt (p. 4I): 'een individu dat zijn eigen werkkring verlaat en zich met zijn kritiek tot een groot publiek richt'. Elke ingezondenbrievenschrijver rond een maatschappelijk thema doet dus mee zou je zeggen, als hij of zij maar niet vanuit eigen werkkring spreekt of schrijft.

In het tweede hoofdstuk, De Kennismaatschappij, onderzoekt Gabriëls wat de sociologie kan bijdragen aan het verhelderen van de genoemde drie kwesties 
rond de positie van de intellectueel. Hij bespreekt een aantal kennissociologische benaderingen zoals het werk van Mannheim, Geiger, Gouldner en Bourdieu. Hij typeert onze samenleving als een kennismaatschappij met zijn grote aantallen kenniswerkers, die participeren in transnationale netwerken en zich druk maken over problemen die transnationaal opgelost moeten worden. Met deze analytische uitgangspunten gewapend (vreemd genoeg keren deze uitgangspunten in de volgende hoofdstukken niet duidelijk terug), gaat Gabriëls drie gevallen van publieke controverse bespreken: in hoofdstuk III De Brede Maatschappelijke Discussie over de kernenergiekwestie, in hoofdstuk IV Het Armoededebat en in hoofdstuk V De Rushdie-affaire.

In het derde hoofdstuk wil Gabriëls de aandacht vestigen op de wijze waarop intellectuelen zich gemengd hebben in de Brede Maatschappelijke Discussie, een unieke want door de regering geënsceneerde openbare discussie over kernenergie (I98I-I986). In de 45 bladzijden die hij hier aan wijdt, is mij volkomen onduidelijk gebleven hoe Gabriëls zijn onderzoek verricht. In noten verwijst hij naar allerlei dagbladen, tijdschriften en documenten, maar de keuze daarvan wordt nergens onderbouwd. Het is dan ook maar raden wat dit betekent voor de selectie die hij gemaakt heeft wat betreft de participerende personen en hoe hij daarbinnen de intellectuelen heeft opgespoord en onderscheiden van hen 'die hun werkkring niet verlaten hebben'. De positie van de intellectueel wordt gekenmerkt door de organisaties namens wie ze spreken, stelt Gabriëls. Ik heb sterk de indruk dat dit komt door de keuze van zijn materiaal. Hij komt met een schematisch onderscheid tussen de woordvoerders van de atoomindustrie en die van de antikernenergiebeweging, een wel erg smalle maatschappelijke discussie.

Het vierde hoofdstuk gaat over het armoededebat, dat gevoerd werd in de jaren tachtig en in 1996 nog een keer oplaaide rond het brood van bisschop Muskens. Gabriëls geeft een schets van het verloop van dit debat en gaat in op enkele centrale publicaties. Ook hier is het onderzoeksdesign duister, geen toegespitste vraagstellingen, niets over sampling of afbakening, geen waarnemingsinstrument (hoe globaal ook) om systematisch kenmerken van het materiaal vast te leggen, niks over analyse. Er worden citaten aangehaald van vertegenwoordigers van de Kerken, van (vooral CDA-)politici en uit werk van sociologen, maar wie nu eigenlijk buiten de eigen werkkring bezig is? Het armoededebat is een publieke controverse over feiten en waarden (p.I74), ja, welk debat niet?

In het vijfde hoofdstuk komt de Rushdie-affaire aan de orde, zoals die zich in Nederland voltrok. De affaire kwam niet voort uit het politieke beleid in Nederland, er was een internationale affaire (de fatwa van Khomeiny tegen Rushdie) die ook politieke consequenties had. Om deze affaire te bespreken, 
vindt Gabriëls het noodzakelijk om het boek De Duivelsverzen (de aanleiding voor de fatwa) uitgebreid te bespreken, een van de sterkere delen van zijn boek. Die bespreking heeft hij vervolgens niet nodig om de bijdragen van de intellectuelen in het debat over deze controverse te benoemen. Gelet op hun inhoudelijke bijdragen zijn er drie groepen te onderscheiden: wetenschappelijke experts (oriëntalisten, islamisten) die om begrip vragen voor de woede van moslims (Biegel, Van Koningsveld, Peters); traditionele intellectuelen die eerdergenoemde experts bestrijden op grond van universeel geldige waarden (Blokker, Tromp, Hofland), en traditionele intellectuelen die de andere intellectuelen bestrijden vanwege hun onverantwoorde generalisaties (Poll, Van Doorn). Het lijkt er dus op dat er alleen maar traditionele experts in Nederland zijn, maar gelukkig is er Gabriëls die Rushdie's boodschap toelicht over universele waarden in lokaal specifieke omstandigheden.

In het laatste hoofdstuk, Tussen Agnosticisme en Moralisme wordt de balans opgemaakt wat betreft de positie van de intellectueel in de samenleving, diens identiteit en verantwoordelijkheid.

Dit boek is volgens de flaptekst niet zomaar een beschrijving van deze publieke interventies, maar intervenieert tevens zelf. Volgens Gabriëls is dat nodig omdat het intellectuele landschap sterk gewijzigd is. Dat blijkt niet uit de besproken controverses. Zo constateert Gabriëls op grond van het Rushdie-debat 'dat de grafredes van onder andere Jacoby, Finkelkraut en Lyotard niet deugen. De traditionele intellectueel is geenszins op sterven na dood' (p. 2I5). Dat de traditionele intellectueel uit de twintigste eeuw tegenwoordig het veld dient te ruimen voor de nieuwe kosmopoliet (wederom flaptekst), volgt dan ook niet uit de analyse van de rol van intellectuelen in deze controverses. De bespreking van die rol is methodisch nogal armoedig. Bovendien is de analyse van de controversen niet systematisch uitgevoerd vanuit vraagstellingen met een bijbehorend interpretatiekader. Hij brengt elk debat terug tot een centrale tegenstelling, die opeens tevoorschijn wordt getoverd. In feite gaat het om een journalistieke samenvatting van een voor mij volkomen onduidelijke selectie van documenten.

Wie de intellectuelen zijn die Gabriëls heeft opgespoord, is mij duister, hoewel bij de Rushdie-affaire enkele namen worden genoemd. Op zijn minst had ik zoiets als 'de tweehonderd van Gabriëls' verwacht (het mogen er ook veertig zijn). Ik mis de analyse van het centrale medium voor debat: de televisiepraatprogramma's. Daarnaast denk ik dat bijvoorbeeld heel wat (regionale) kranten ingezonden brieven bevatten van mensen 'die hun werkkring hebben verlaten' en zich in een dergelijk debat hebben gemengd. De titel is dan ook volkomen misplaatst. Gelet op de beschrijving van het handjevol goedgekeurde kosmopolieten in het laatste hoofdstuk gaat het hier om een wel erg lokaal fenomeen. 